OPEN ACCESS

Edited by:

Inês A. Cardoso Pereira, Instituto de Tecnologia Química e Biológica (ITQB-NOVA), Portugal

Reviewed by: Simon Colin Andrews, University of Reading, United Kingdom

Robert Maier,

University of Georgia, United States

*Correspondence: Marilis V. Marques mvmarque@usp.br

Specialty section: This article was submitted to Microbial Physiology and Metabolism,

a section of the journa

Frontiers in Microbiology

Received: 01 April 2018 Accepted: 09 August 2018

Published: 28 August 2018

Citation

Leaden L, Silva LG, Ribeiro RA dos Santos NM, Lorenzetti APR Alegria TGP, Schulz ML,

Medeiros MHG, Koide T and Marques MV (2018) Iron Deficiency

Generates Oxidative Stress and Activation of the SOS Response

in Caulobacter crescentus.

Front. Microbiol. 9:2014. doi: 10.3389/fmicb.2018.02014

\section{Iron Deficiency Generates Oxidative Stress and Activation of the SOS Response in Caulobacter crescentus}

Laura Leaden', Larissa G. Silva', Rodolfo A. Ribeiro', Naara M. dos Santos', Alan P. R. Lorenzetti ${ }^{2}$, Thiago G. P. Alegria ${ }^{3}$, Mariane L. Schulz ${ }^{4}$, Marisa H. G. Medeiros, Tie Koide ${ }^{2}$ and Marilis V. Marques ${ }^{1 *}$

${ }^{1}$ Departamento de Microbiologia, Instituto de Ciências Biomédicas, Universidade de São Paulo, São Paulo, Brazil, ${ }^{2}$ Departamento de Bioquímica e Imunologia, Faculdade de Medicina de Ribeirão Preto, Universidade de São Paulo, Ribeirão Preto, Brazil, ${ }^{3}$ Departamento de Genética e Biologia Evolutiva, Instituto de Biociências, Universidade de São Paulo, São Paulo, Brazil, ${ }^{4}$ Departamento de Bioquímica, Instituto de Química, Universidade de São Paulo, São Paulo, Brazil

In C. crescentus, iron metabolism is mainly controlled by the transcription factor Fur (ferric uptake regulator). Iron-bound Fur represses genes related to iron uptake and can directly activate the expression of genes for iron-containing proteins. In this work, we used total RNA sequencing (RNA-seq) of wild type C. crescentus growing in minimal medium under iron limitation and a fur mutant strain to expand the known Fur regulon, and to identify novel iron-regulated genes. The RNA-seq of cultures treated with the iron chelator 2-2-dypiridyl (DP) allowed identifying 256 upregulated genes and 236 downregulated genes, being 176 and 204 newly identified, respectively. Sixteen transcription factors and seven sRNAs were upregulated in iron limitation, suggesting that the response to low iron triggers a complex regulatory network. Notably, lexA along with most of its target genes were upregulated, suggesting that DP treatment caused DNA damage, and the SOS DNA repair response was activated in a RecAdependent manner, as confirmed by RT-qPCR. Fluorescence microscopy assays using an oxidation-sensitive dye showed that wild type cells in iron limitation and the fur mutant were under endogenous oxidative stress, and a direct measurement of cellular $\mathrm{H}_{2} \mathrm{O}_{2}$ showed that cells in iron-limited media present a higher amount of endogenous $\mathrm{H}_{2} \mathrm{O}_{2}$. A mutagenesis assay using the $r p o B$ gene as a reporter showed that iron limitation led to an increase in the mutagenesis rate. These results showed that iron deficiency causes $C$. crescentus cells to suffer oxidative stress and to activate the SOS response, indicating an increase in DNA damage.

Keywords: iron limitation, DNA damage, Caulobacter crescentus, oxidative stress, RNA-seq analysis

\section{INTRODUCTION}

The metal iron is an essential micronutrient for bacterial growth. Under physiological conditions, it exists mainly in one of two redox states: the ferrous $\left(\mathrm{Fe}^{2+}\right)$ form and the ferric $\left(\mathrm{Fe}^{3+}\right)$ form. Iron is a prosthetic component for incorporation into proteins, and participates in important biological processes such as $\mathrm{N}_{2}$ fixation, tricarboxylic acid cycle, respiration, gene regulation, and DNA synthesis (Beinert et al., 1997; Andrews et al., 2003). Iron is not freely available in the 
environment since ferric iron is extremely insoluble, so bacteria have evolved strategies to ensure their physiological demands. Iron limitation leads to increased iron influx, the reduction in activity of non-essential iron enzymes, the activation of ironindependent pathways and the mobilization of protein-associated stored iron, as from ferritins. On the other hand, excess iron induces genes involved in its efflux and reduction of iron uptake to keep intracellular iron levels under strict regulation (Chandrangsu et al., 2017). This control, along with the activation of oxidative stress response, is an essential factor to allow the aerobic style of life (Touati, 2000).

C. crescentus is an aerobic free-living alphaproteobacterium that grows in oligotrophic aquatic environments, and despite apparently not synthesizing its own siderophores for iron uptake, is able to acquire them through TonB-dependent transporters (Balhesteros et al., 2017). In C. crescentus, four TonB-dependent transporters predicted to be involved in iron acquisition are regulated by Fur, and one of them was characterized as the hemin/hemoglobin transporter HutA (da Silva Neto et al., 2009; Balhesteros et al., 2017).

In most bacteria, the transcriptional regulator Fur tightly controls iron homeostasis (Fillat, 2014). Iron-bound Fur acts as transcriptional repressor under iron sufficient conditions, inhibiting the expression of genes for iron uptake and for non-essential iron enzymes (Andrews et al., 2003; Lee and Helmann, 2007). In several bacteria the repression by iron-Fur is released under iron limitation, allowing the expression of a small RNA (called RyhB in Escherichia coli, FsrA in Bacillus subtilis, PrrF1 and PrrF2 in Pseudomonas aeruginosa, NrrF in Neisseria meningitidis, and Bc_KC_sr1 and Bc_KC_sr2 in Burkholderia cenocepacia $\mathrm{KC}-01$ ), which facilitates the degradation of the mRNA of non-essential iron enzymes (Masse and Gottesman, 2002; Wilderman et al., 2004; Masse et al., 2005, 2007; Mellin et al., 2007; Gaballa et al., 2008; Ghosh et al., 2017; Jackson et al., 2017).

Previously, a detailed in silico analysis of the promoter regions of the nuoA-N operon (NADH dehydrogenase), acnA (aconitase) and $s d h C B A D$ (succinate dehydrogenase), confirmed by electrophoresis mobility shift assays, showed that Fur directly binds to these regulatory regions and activates the expression of these genes in response to iron (da Silva Neto et al., 2009), revealing that in $C$. crescentus the mechanism of iron control of metabolism is different than that of $E$. coli. Global transcriptional analyses using DNA microarrays allowed to define the Fur regulon, identifying 42 genes repressed and 27 genes activated by Fe-Fur (da Silva Neto et al., 2013).

In $C$. crescentus, Fur also activates the low oxygen signaling network FixK, FixT and FtrB cascade, suggesting that in C. crescentus iron regulation also can be sensitive to $\mathrm{O}_{2}$ levels (da Silva Neto et al., 2013). In E. coli, an anaerobic facultative bacterium, Fur activity is modulated by $\mathrm{O}_{2}$ levels (Beauchene et al., 2015). It has been reported that in anaerobic conditions the labile iron pool is higher than in aerobic conditions (Beauchene et al., 2017). Under anaerobic condition the upregulation of feo $A B C$ transport system facilitates the $\mathrm{Fe}^{2+}$ import increasing the labile iron pool, which is required to enhance the Fur regulon in these conditions (Beauchene et al., 2015, 2017).
The previous transcriptional analysis also showed that several genes have an iron-dependent and Fur-independent regulation in $C$. crescentus, such as those encoding the heat shock sigma factor $\mathrm{RpoH}$ and the $\mathrm{Fe}-\mathrm{S}$ cluster biogenesis operon containing iscR (da Silva Neto et al., 2013). However, the tiling array platform used consisted of primers located mainly around the start codons of annotated protein-coding genes. As previous works using high-throughput RNA sequencing have identified an expressive number of non-coding RNAs that could participate in gene regulation (Landt et al., 2008; Schrader et al., 2014), it is important to identify those that participate in the regulatory network that control the response to iron levels.

In order to further understand the consequences of iron limitation, we carried out an RNA-seq-based transcriptomic analysis seeking to identify new genes responsive to iron limitation and belonging to the Fur regulon, as well as ironregulated regulatory RNAs. Our analyses showed that under iron limitation several stress response genes are induced, and the cells are in a state of oxidative stress. Moreover, the results indicate that in $C$. crescentus under iron limitation, the genes involved in the SOS response are induced in a RecA-dependent manner, suggesting that in this condition the cells undergo DNA damage.

\section{MATERIALS AND METHODS}

\section{Bacterial Strains and Growth Conditions}

The Caulobacter crescentus strains used were: NA1000 (wildtype) (Evinger and Agabian, 1977), SP0057 (fur mutant) (da Silva Neto et al., 2009), GM10 (recA mutant) (Galhardo et al., 2005), and NA1000 and GM10 harboring the pRKlacZ290 vector containing the imuA promoter (imuA/lacZ fusion) (Galhardo et al., 2005). Cultures were grown aerobically at $30^{\circ} \mathrm{C}$ in minimal medium (M2), which contains $10 \mu \mathrm{M} \mathrm{FeSO}_{4}$ (Ely, 1991). Ironlimiting conditions were obtained by adding the iron chelator 2,2-dipyridyl (DP) (Sigma, $100 \mu \mathrm{M}$ ) to the M2 medium (DPtreated M2) or by using a modified M2 medium without iron sulfate (iron-limited M2). Excess iron conditions were achieved by supplementing M2 medium with $100 \mu \mathrm{M} \mathrm{FeSO}$ instead of $10 \mu \mathrm{M} \mathrm{FeSO}_{4}$. The growth curves in each condition are shown in Supplementary Figure S1.

\section{RNA-seq Expression Profiling}

The NA1000 and SP0057 strains (pre-cultivated in $3 \mathrm{ml} \mathrm{M} 2$ overnight) were diluted in duplicate into $10 \mathrm{ml} \mathrm{M} 2$ to an $\mathrm{OD}_{600 \mathrm{~nm}}$ of 0.1 and incubated at $30^{\circ} \mathrm{C}$ with agitation $(250 \mathrm{rpm})$ until reaching $\mathrm{OD}_{600 \mathrm{~nm}}$ of 0.5 . At this time $\mathrm{DP}$ was added to a final concentration of $100 \mu \mathrm{M}$ to one aliquot of the NA1000 culture and these were further incubated for $2 \mathrm{~h}$. Total RNA was isolated from independent cultures $(1 \mathrm{ml})$ treated with RNAprotect Bacteria Reagent (Qiagen) and purified with Qiagen RNeasy Plus Mini Kit (Qiagen). RNA samples were quantified using NanoDrop 1000 (Thermo Scientific) and submitted to the removal of ribosomal RNA using Ribo-Zero Magnetic kit (Illumina). The quality of the isolated RNA and the percentage of rRNA present were checked with RNA 6000 Pico Kit using Agilent 2100 Bioanalyzer (Agilent). Complementary DNA was 
generated according to instructions of TruSeq RNA Sample Prep Kit (Illumina). The cDNA libraries were normalized to $4 \mathrm{nM}$ using the Kapa Biosystems kit (Kapa Biosystems) for library quantitation prior to cluster generation. The samples were sequenced using the MiSeq (Illumina) platform according to the manufacturer's instructions. RNA-seq experiments were carried out in biological duplicates.

cDNA reads were quality checked using Bioconductor's 3.5 (Huber et al., 2015) Rqc 1.10 .2 and trimmed using Trimmomatic 0.36 (Bolger et al., 2014) to remove adapters and low quality ends. Pre-processed reads were aligned to C. crescentus NA1000 reference genome using Bowtie 1.2 (Langmead et al., 2009) with the "-m 1" option to keep only uniquely mapped reads. Alignment files were further processed by SAMtools 1.3.1 ( $\mathrm{Li}$ et al., 2009) and read counting was performed for each gene feature using GenomicAlignments 1.12.1 (Lawrence et al., 2013). The count matrix was input in DESeq2 1.16.1 (Love et al., 2014) and analyzed using group design. We generated two contrasts to find differentially expressed genes: (i) wt DP-treated for $2 \mathrm{~h}$ vs. wt and (ii) fur mutant vs. wt. Genes were considered differentially expressed if satisfying $\mid \log _{2}$ fold change $\mid \geq 1$ and $q$-value $<0.05$. We used information available in KEGG pathways (Kanehisa et al., 2017) to group differentially expressed genes in functional categories and also performed manual curation.

\section{Real-Time PCR}

The gene expression profile was assessed by RT-qPCR. Cultures pre-cultivated in $3 \mathrm{ml} \mathrm{M} 2$ overnight were diluted into two aliquots of $10 \mathrm{ml} \mathrm{M} 2$ to an $\mathrm{OD}_{600 \mathrm{~nm}}$ of 0.05 and incubated at $30^{\circ} \mathrm{C}$ with agitation $(250 \mathrm{rpm})$ until reaching $\mathrm{OD}_{600 \mathrm{~nm}}$ of 0.3 . At this time DP was added to one aliquot to a final concentration of $100 \mu \mathrm{M}$ and these were further incubated for $2 \mathrm{~h}$. When iron limited M2 was used, the overnight culture was diluted in $10 \mathrm{ml}$ $\mathrm{M} 2$, and when the cultures reached an $\mathrm{OD}_{600 \mathrm{~nm}}$ of 0.3 they were centrifuged for $20 \mathrm{~min}$ at 5,000 $\times g$ and resuspended in the same volume of iron limited M2 (no iron added). One of the aliquots received $\mathrm{FeSO}_{4}$ to a final concentration of $10 \mu \mathrm{M}$, and the cultures were incubated at $30^{\circ} \mathrm{C}$ until the appropriate time. Total RNA was isolated from $5 \mathrm{ml}$ cultures either in M2, iron limited M2 (with no iron addition) or DP-treated M2 for $2 \mathrm{~h}$ as indicated for each experiment. RNA was purified using TRIzol $^{\circledR}$ RNA (Invitrogen), treated with deoxyribonuclease I (Invitrogen) and complementary DNA was synthesized using the Superscript III First-Strand Synthesis System kit for RTPCR (Invitrogen) with random hexamers. RT-qPCR reactions were performed on the Step One Plus Real Time PCR System (Applied Biosystems), using SYBR Green PCR Master Mix (Applied Biosystems) as detection reagent, in technical triplicates. RT-qPCR reactions were carried out in a final volume of $12 \mu \mathrm{l}$ Power SYBR Green PCR master mix containing $10 \mu \mathrm{M}$ of each primer, and $50 \mathrm{ng} \cdot \mathrm{\mu l}^{-1} \mathrm{cDNA}$. The conditions were $95^{\circ} \mathrm{C}$ for $10 \mathrm{~min}$, followed by 40 cycles comprising $95^{\circ} \mathrm{C}$ for $15 \mathrm{~s}$ and $60^{\circ} \mathrm{C}$ for $1 \mathrm{~min}$. In order to confirm the amplification of a single product, dissociation curves were generated at the end of each PCR cycle. The $2^{-\Delta \Delta C t}$ method was used to calculate the relative change in gene expression of each gene (Pfaffl, 2001), and the analysis was performed using the StepOne Software v.2.2. Specific primers were designed using primer3 software (Untergasser et al., 2012) for each gene for validation of RNA-seq data and gene CCNA_03876, coding the transcription termination factor Rho, used as reference control (Supplementary Table S1). All determinations were performed in biological duplicates and at least in technical triplicates and the mean values \pm standard deviation (SD) are reported.

\section{$\beta$-Galactosidase Activity Assays}

C. crescentus NA1000 or $\triangle$ recA strains harboring the pRKlacZ290 vector containing the imuA promoter (imuA/lacZ fusion) were grown in M2 medium up to midlog phase $\left(\mathrm{OD}_{600} \mathrm{~nm}\right.$ of 0.2 ). Each culture of NA1000 was divided into four equal aliquots, and one was left without additions throughout the experiment. To two other aliquots, either $100 \mu \mathrm{M} \mathrm{FeSO}_{4}$ (called iron-added M2) or $100 \mu \mathrm{M}$ DP (called DP-treated M2) were added. The fourth aliquot was centrifuged and the cells were suspended in M2 medium without iron (called iron-limited M2). In the assays with the $\Delta r e c A$ strain, the culture was divided in two aliquots, one without additions and the second received $100 \mu \mathrm{M}$ DP. The cultures were further incubated during the appropriate times and the $\beta$-galactosidase activity was determined (Miller, 1972).

\section{Microscopy}

C. crescentus NA1000 and the fur mutant were grown in M2 medium up to midlog phase $\left(\mathrm{OD}_{600} \mathrm{~nm}\right.$ of $\left.0.2-0.3\right)$. Each C. crescentus NA1000 culture was divided into equal aliquots, and one was left without additions throughout the experiment. To one other aliquot, DP to $100 \mu \mathrm{M}$ was added and the cultures were further incubated for $2 \mathrm{~h}$. One aliquot was centrifuged and the cells were suspended in the same volume of M2 medium without iron (iron-limited M2) for $4 \mathrm{~h}$. To one of the aliquots $\mathrm{H}_{2} \mathrm{O}_{2}$ was added to $10 \mathrm{mM}$ and incubated for $15 \mathrm{~min}$. In the assays with the fur strain, the culture was divided in two aliquots, one was left without additions and the second received DP as above. Dihydrorhodamine 123 (Sigma D1054) was added to the cultures to a final concentration of $20 \mu \mathrm{M}$ and the cultures were further incubated for $60 \mathrm{~min}$. After the cells were washed they were resuspended in phosphate-buffered saline solution. The slides were observed using a fluorescein filter in a Nikon Eclipse TiE microscope, using a $100 \times$ objective and images were captured in an Andor EM CCD i-Xon camera.

\section{Survival and Mutagenesis Tests}

For the mutagenesis tests, cultures of the C. crescentus NA1000 and $\operatorname{rec} A$ strain were grown for $10 \mathrm{~h}$ in $10 \mathrm{ml}$ of $\mathrm{M} 2$ medium. The cells from each culture were pelleted by centrifugation for $20 \mathrm{~min}$ at 5,000 $\times g$ and resuspended in iron limited M2 (no iron added) to the same previous volume. The cultures were adjusted to $\mathrm{OD}_{600 \mathrm{~nm}}$ of 0.2 , and divided into two $5 \mathrm{ml}$ aliquots. One of the aliquots received $\mathrm{FeSO}_{4}$ to a final concentration of $10 \mu \mathrm{M}$, and the cultures were incubated at $30^{\circ} \mathrm{C}$ with agitation for $12 \mathrm{~h}$. One $\mathrm{ml}$ of each culture was centrifuged at 5,000 $\times g$ and the cells were resuspended in $1 \mathrm{ml} \mathrm{M} 2$. Two hundred microliters were diluted in $1 \mathrm{ml} \mathrm{M} 2$ and incubated at $30^{\circ} \mathrm{C}$ with agitation for $24 \mathrm{~h}$. Serial dilutions and plating on PYE were performed to determine 
the total number of viable cells. To determine the number of Rif-resistant mutants, $1 \mathrm{ml}$ of each culture was plated on PYE medium containing $100 \mu \mathrm{g} / \mathrm{ml}$ rifampicin.

For the UV survival tests, C. crescentus NA1000, SP0057 and GM10 overnight cultures were diluted to an optical density at $600 \mathrm{~nm}\left(\mathrm{OD}_{600 \mathrm{~nm}}\right)$ of 0.05 in M2 medium. Each culture was divided into three equal aliquots, and to one (control) no additions were made throughout the experiment. One aliquot of the NA1000 culture was pre-incubated with $100 \mu \mathrm{M}$ DP for $2 \mathrm{~h}$. One aliquot was centrifuged and the cells were suspended in ironlimited M2 for the appropriate times. After the respective times, each culture was irradiated with $120 \mathrm{~J} / \mathrm{cm}^{2} \mathrm{UV}$ light (NA1000), $60 \mathrm{~J} / \mathrm{cm}^{2}$ (SP0057) and $10 \mathrm{~J} / \mathrm{cm}^{2}$ (GM10). Serial dilutions from each control and treated cultures were plated on M2 plates, and these were incubated in the dark for $48 \mathrm{~h}$ at $30^{\circ} \mathrm{C}$ for $\mathrm{CFU}$ counting.

\section{Analysis by HPLC-ESI/MS/MS of 8-oxo-dG}

DNA extraction and enzymatic hydrolysis was carried out as described in Sanchez et al. (2018) with the following modifications. The bacterial pellet was resuspended in lysis buffer containing $0.1 \mathrm{mM}$ desferroxamine. Treatment with $60 \mu \mathrm{L}$ of proteinase $\mathrm{K}(20 \mathrm{~g} / \mathrm{L})$ was performed together with $675 \mu \mathrm{L}$ of a $10 \%(\mathrm{w} / \mathrm{v})$ solution of SDS for $2 \mathrm{~h}$ at $37^{\circ} \mathrm{C}$. The DNA pellet was solubilized in a $3 \mathrm{mM}$ solution of desferroxamine mesylate, and concentration was measured by $A_{260 \mathrm{~nm}}$. For the hydrolysis of $30 \mu \mathrm{g}$ of DNA, $5 \mu \mathrm{l}$ of $3 \mathrm{M}$ sodium acetate buffer $\mathrm{pH} 5.0$ and $4 \mathrm{U}$ of nuclease $\mathrm{P} 1$ were added to the sample, which was incubated at $37^{\circ} \mathrm{C}$ for $30 \mathrm{~min}$ at $450 \mathrm{rpm}$. Following this step, $5 \mu \mathrm{l}$ of $3 \mathrm{M}$ Tris-Cl buffer $\mathrm{pH} 7.4$ and $5 \mu \mathrm{l}$ of phosphatase buffer containing $100 \mathrm{mM}$ Tris-Cl, $5 \mathrm{mM} \mathrm{MgCl}_{2}, 0.2 \mathrm{mM} \mathrm{ZnCl}_{2}$ and $50 \%(\mathrm{v} / \mathrm{v})$ glycerol were added. After addition of $2 \mathrm{U}$ of alkaline phosphatase, the reaction mixture was incubated at $37^{\circ} \mathrm{C}$ for $1 \mathrm{~h}$ at $450 \mathrm{rpm}$.

Online HPLC/ESI/MS-MS analyses were carried out as described in Garcia et al. (2010) using an API-4000 QTRAP mass spectrometer (Applied Biosystems, Foster City, CA, United States). 8-oxo-dG in the DNA samples were detected by selected reaction monitoring (SRM) using an analytical column (Luna C18(2), $250 \mathrm{~mm} \times 4.6 \mathrm{~mm}$ i.d., $5 \mu \mathrm{m}$, Phenomenex, Torrance, CA, United States). 8-oxo-dG was eluted from this column with a gradient of water and acetonitrile containing $0.1 \%$ formic acid with the following method: from 0 to $10 \mathrm{~min}, 5$ to $12 \%$ acetonitrile, and 0.5 to $0.25 \mathrm{~mL} / \mathrm{min}$; from 10 to $15 \mathrm{~min}$, $12 \%$ acetonitrile and $0.25 \mathrm{~mL} / \mathrm{min}$; from 15 to $40 \mathrm{~min}, 12$ to $40 \%$ acetonitrile and $0.25 \mathrm{~mL} / \mathrm{min}$; from 40 to $41 \mathrm{~min}, 40$ to $95 \%$ acetonitrile and 0.25 to $0.5 \mathrm{~mL} / \mathrm{min}$; from 41 to $45 \mathrm{~min}$, $95 \%$ acetonitrile and $0.5 \mathrm{~mL} / \mathrm{min}$; from 45 to $46 \mathrm{~min}, 95$ to $5 \%$ acetonitrile and $0.5 \mathrm{~mL} / \mathrm{min}$; from 46 to $50 \mathrm{~min}, 5 \%$ acetonitrile and $0.5 \mathrm{~mL} / \mathrm{min}$. An isocratic pump was used to simultaneously load a second column [Luna C18(2), $150 \mathrm{~mm} \times 2 \mathrm{~mm}$ i.d., $3 \mu \mathrm{m}$, Phenomenex, Torrance, CA, United States]. The DNA hydrolysates containing $3.6 \mathrm{fmol}$ of the [15N5]-8-oxo-dG internal standards were injected into the system described above. The $[\mathrm{M}+\mathrm{H}]+$ ions corresponding to the $\mathrm{m} / \mathrm{z}$ values $284.1 / 167.9$
(8-oxo-dG) and 289.1/172.9 ([15N5]-8-oxo-dG), were monitored with a dwell time of $150 \mathrm{~ms}$.

\section{$\mathrm{H}_{2} \mathrm{O}_{2}$ Dosage Assays}

Colonies from the NA1000 strain were inoculated in $3 \mathrm{ml}$ of M2 medium and grown for $16 \mathrm{~h}$ at $30^{\circ} \mathrm{C}$ with agitation. These two independent cultures (biological replicas) were then diluted to an $\mathrm{OD}_{600 \mathrm{~nm}}$ of 0.1 in $15 \mathrm{ml}$ of $\mathrm{M} 2$ and incubated at $30^{\circ} \mathrm{C}$ with agitation until reaching an OD of 0.25 . The cultures were divided into four $7 \mathrm{ml}$ aliquots, and cells were pelleted by centrifugation for $20 \mathrm{~min}$ at 5,000 rpm. Cells from two aliquots were suspended in M2 and from the other two in iron limited M2 (no iron added) in the same previous volume. One culture in M2 and one culture in iron limited M2 received DP to a final concentration of $100 \mu \mathrm{M}$ for each replica. The cultures were incubated for $3 \mathrm{~h}$ at $30^{\circ} \mathrm{C}$ with agitation. For the assays $1.5 \mathrm{ml}$ from each culture was centrifuged at $12,000 \times g$ and the cells resuspended in $100 \mu \mathrm{l}$ of $20 \mathrm{mM}$ Tris-Cl pH 7.4.

Determination of the amount of $\mathrm{H}_{2} \mathrm{O}_{2}$ was carried out as described in Barros et al. (2003). Briefly, $50 \mu \mathrm{l}$ of each bacterial suspensions were added to $3 \mathrm{ml}$ of a solution containing $50 \mu \mathrm{M}$ Amplex Red (Thermo Scientific) and 1.0 $\mathrm{U} / \mathrm{ml}$ horseradish peroxidase (HRP; Sigma-Aldrich), in $20 \mathrm{mM}$ Tris- $\mathrm{Cl} \mathrm{pH} \mathrm{7.4.} \mathrm{The} \mathrm{rate} \mathrm{of} \mathrm{Amplex} \mathrm{Red} \mathrm{oxidation} \mathrm{to} \mathrm{the}$ fluorescent product (resorufin) was analyzed at $25^{\circ} \mathrm{C}$ using a Cary Eclipse (Varian) fluorescence spectrophotometer equipped with continuous stirring.

\section{Statistical Analyses}

Error bars shown on graphs indicate standard deviations or standard error, as indicated. Statistical significance was tested by one-way ANOVA using the Tukey post-test for multiple comparisons or by $t$-test when only two conditions were being compared.

\section{RESULTS}

\section{Expanding the Low Iron Stimulon in C. crescentus}

Previous works using DNA microarrays and bioinformatics have characterized the iron limitation response in C. crescentus in the rich amino acid-based medium PYE (da Silva Neto et al., 2009, 2013). In that case, $\mathrm{PYE}$ was supplemented with $100 \mu \mathrm{M} \mathrm{FeSO}_{4}$ or $100 \mu \mathrm{M}$ DP, respectively, to allow identification of differentially expressed genes. In order to further characterize the response to iron limitation of this oligotrophic bacterium, RNA-seqbased global transcriptional analysis was performed from cells grown in M2 minimal medium. The RNA-seq experiments were carried out using RNA samples prepared from two independent biological cultures. To define the C. crescentus iron-regulated genes we compared the transcriptome of wt cells grown in M2 treated or not with the iron chelator $2^{\prime}, 2$-dypiridyl for $2 \mathrm{~h}$ (DPtreated). The addition of DP significantly altered the expression of 492 genes (256 upregulated genes and 236 downregulated genes) (Figure 1). To identify the genes regulated by Fur, we 


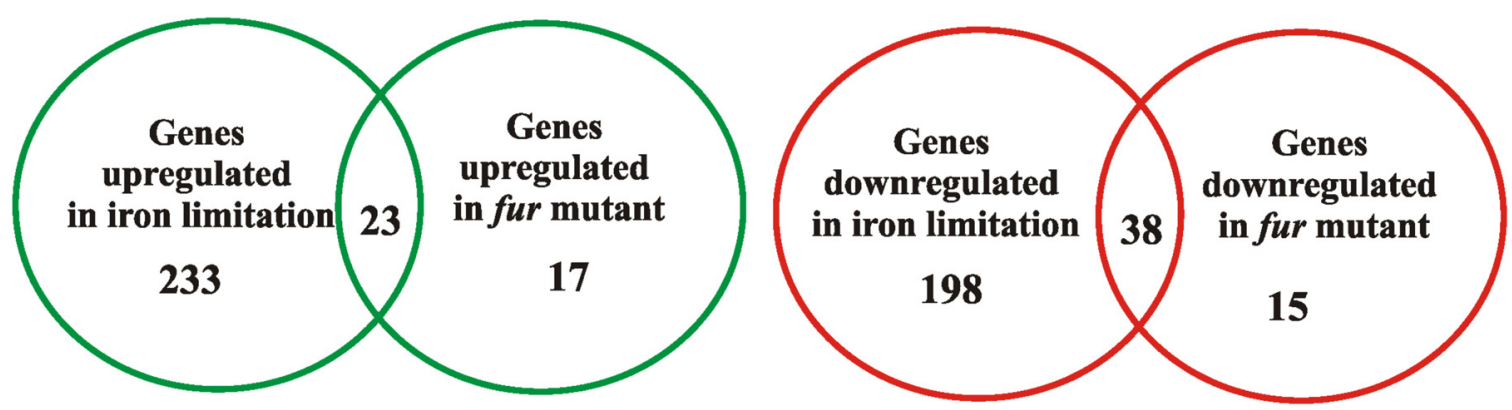

FIGURE 1 | Overview of the C. crescentus iron-regulated and Fur-regulated genes identified by RNA-seq analyses. The Venn diagrams indicate the number of up-regulated (green) and down-regulated (red) genes from experiments comparing wild type cells exposed to DP-treated M2 versus M2 or comparing the fur mutant strain versus wild type strain both in M2. Differentially expressed genes were considered those with $\log _{2}$ fold change $\geq 1$ or $\leq 1$ and $q$-value $<0.05$.

compared the transcriptome of wt cells with the fur mutant in M2. Overall, 93 genes were differentially expressed in the fur mutant (40 upregulated genes and 53 downregulated genes) (Figure 1).

We found 23 genes upregulated and 38 genes downregulated both in DP-treated condition and in the fur mutant (Supplementary Table S2). Seventy-four percent (17 genes) of the upregulated genes were genes previously identified by DNA microarray analysis in PYE, and six genes are new. Of these, four genes encoded hypothetical proteins, one a serine protease (CCNA_01341) and another the amelogenin/CpxP-related protein (CCNA_03997). Of the 38 downregulated genes, 11 genes were previously known as iron- and Fur-regulated in PYE, and 17 genes belong to the regulon controlled by FixL-FixK-FixT, among them the cytbb3 operon (CCNA_01467-68-69-70-71-7273), CCNA_01475 encoding the family outer membrane cation channel (ompW) and CCNA_01476-77 that encode the CRPfamily transcription regulator $(f t r B)$ and oxygen-independent coproporphyrinogen-III oxidase $(h e m N)$. In agreement with the results obtained with DNA microarrays, these data indicate that Fur might activate, probably indirectly, the oxygen signaling network.

In general, the Fur regulon determined in M2 (23 genes) was smaller than that previously determined in PYE (42 genes), while the number of genes induced only in DPtreated condition was larger in M2 (233 genes versus 66 genes upregulated in PYE). Interestingly, some genes that are regulated by Fur and were highly responsive to DP-treatment in PYE (da Silva Neto et al., 2009, 2013) did not show an increase in their transcript levels in DP-treated M2 medium. For example, CCNA_03023 that encodes a TonB-dependent receptor and CCNA_02275 that were upregulated gene in DPtreated PYE (15.3- and 64.8-fold, respectively) were below the cutoff in our experimental conditions. Still, these genes were upregulated in the fur mutant (CCNA_03023, 3.3-fold and CCNA_02275 5-fold), confirming that their expression is under Fur regulation, although the levels of expression are differently modulated according to the culture medium (Supplementary Table S2).

Eight previously predicted sRNAs (Landt et al., 2008; Schrader et al., 2014) were identified as differentially expressed in our experiments. One of these (R0117) was upregulated both in DPtreated condition (16.3-fold) and in the fur mutant (3.6-fold). This gene encodes a 1-kb RNA that maps to a region where previously annotated transcripts were shown to be regulated by Fur (da Silva Neto et al., 2013). One sRNA gene (R0088) was upregulated only in the fur mutant (7.7-fold), while six (R0180, R0119, R0116, R0049, R0080, and R0077) were upregulated only in DP-treated condition, varying from 3.6-fold for R0077 to 45.7fold for R0180 (Supplementary Table S2). We could not identify a conserved Fur-box upstream of any of the sRNAs, including R0088, suggesting that it is indirectly regulated by Fur. The other six sRNAs could be important for the iron limitation response, in a Fur-independent manner, possibly regulating the expression of subsets of genes.

\section{Several Transcription Factors Are Induced in Iron Limitation}

In M2 treated with DP the induction of 16 genes encoding transcription regulators was observed (Supplementary Table S2), of which several are involved in controlling stress response in C. crescentus. These include the RNA polymerase sigma factor $r p o H$ (8.5-fold) and three ECF sigma factors $\left(\sigma^{\mathrm{E}}, \sigma^{\mathrm{T}}\right.$, and $\sigma^{\mathrm{U}}, 5.9-, 5.5-$, and 12.7 -fold, respectively) as well as the $\sigma^{\mathrm{T}}$ regulatory systems LovR/LovK (lovR, 5.3-fold) and PhyR/PhyK/NepR (3.9-, 4.8-, and 6.7-fold, respectively) (Foreman et al., 2012). While the RpoH and several heat shock genes were previously identified as induced in DP-treated PYE (da Silva Neto et al., 2013), the other systems were identified only in the conditions used in this work. Surprisingly, the lexA gene encoding the SOS system regulator was also induced in DP-treated condition (8.4-fold), along with many genes belonging to the LexA regulon that will be discussed below (Supplementary Table S2). fur was not classified as upregulated in RNA-seq analysis although it presented a twofold induction, because it did not attend our statistical criteria. To further verify the expression of these regulators under iron limitation, we used RT-qPCR to measure the transcript levels of fur, rpoH, and sigT. The results show that all genes were induced in iron limitation generated by resuspending the cells in M2 without added iron (Figure 2). 


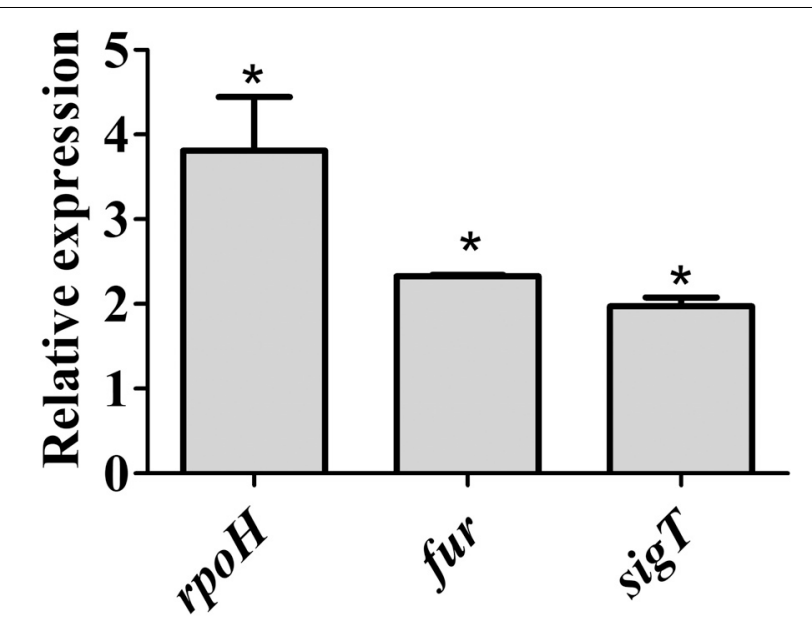

FIGURE 2 | Expression of fur, sigT, and rpoH in wild type strain under iron limitation. Gene expression was determined by RT-qPCR using RNA from cells grown in iron limited M2 (for $4 \mathrm{~h}$ ) relative to the expression in M2. Bars with asterisks $\left({ }^{*}\right)$ are significantly different to wt growing in M2 medium $(P<0.05)$ by Student's $t$-test.

\section{Iron Deficiency Induces the SOS Response}

To discriminate whether the upregulation of genes belonging to the SOS response was caused by iron limitation or due to a secondary effect of the iron chelator used, the expression of the $i m u A$-imuB-dnaE2 operon was measured by $\beta$-galactosidase activity using a transcriptional fusion to lacZ (PimuA-lacZ) (Figure 3). This operon is induced in response to DNA lesions in a RecA-dependent manner, and the three genes are required for the error-prone processing of DNA lesions (Galhardo et al., 2005). The results showed that imuA is induced under iron limitation conditions in both DP-treated M2 (containing the chelator DP) and in iron-limited M2 (no iron added), compared to M2 or iron-supplemented M2. The levels of $\beta$-galactosidase activity were slightly different between DP-treated M2 and ironlimited M2, but both were higher than the controls. These results indicated that the SOS response is being activated by iron limitation, suggesting that DNA damage is occurring in this condition. In order to verify if imuA induction was in fact responding to the SOS regulators, we analyzed imuA expression in the recA mutant (Figure 3). The results showed that the induction of $i m u A$ under iron limitation is dependent on RecA, indicating that it was induced by the SOS regulatory system.

\section{Iron Deficiency Generates Oxidative Stress}

The genes encoding the catalase-peroxidase and two superoxide dismutases, as well as several genes coding for oxidative stress response (glutaredoxin, glutathione $S$-transferase, peroxiredoxin, glutathione synthetase, thioredoxin) were upregulated upon DPtreated conditions (Supplementary Table S2). To determine if the reason for the activation of SOS response could be a state of

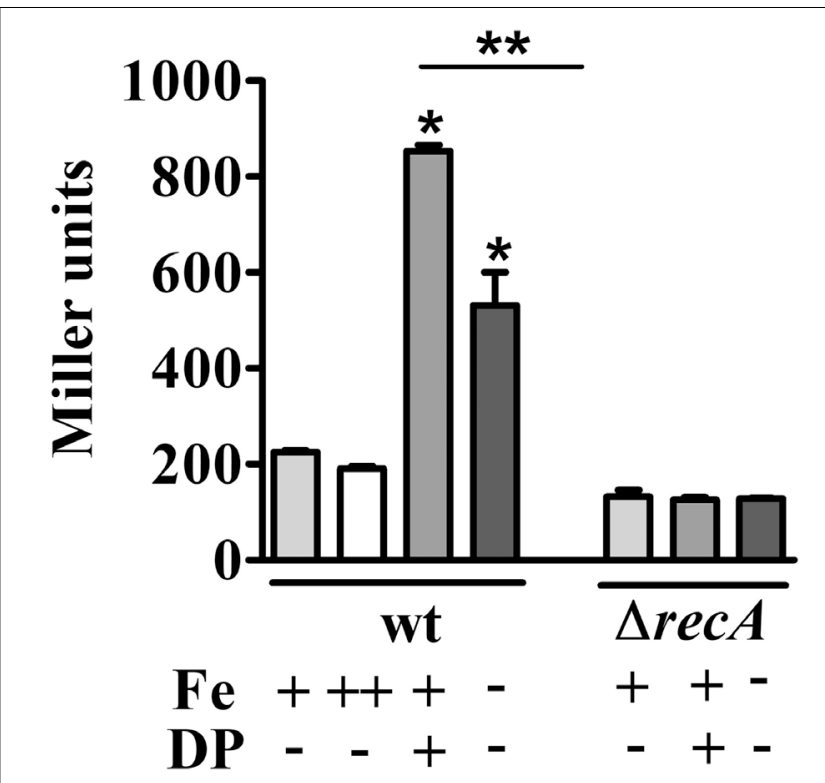

FIGURE 3 | Determination of iron-dependent regulation of imuA expression. Expression was determined by $\beta$-galactosidase activity assays of each strain harboring imuA/lac $Z$ transcriptional fusions. Cultures were grown in either $\mathrm{M} 2$ (Fe+/DP-), iron-supplemented M2 (with $100 \mu \mathrm{M} \mathrm{FeSO}_{4}, \mathrm{Fe}++/ \mathrm{DP}-$ ), DP-treated M2 for $4 \mathrm{~h}$ (with $100 \mu \mathrm{M} \mathrm{DP}, \mathrm{Fe}+/ \mathrm{DP}+$ ) or iron-limited M2 (Fe-/DP-) for $4 \mathrm{~h}$. The $\triangle$ recA mutant was grown in the same conditions, except for iron supplemented M2. Bars with asterisks $\left(^{*}\right)$ are significantly different to wt grown in M2; and $\left(^{* *}\right)$ indicates that results from DP-treated M2 and iron-limited $\mathrm{M} 2$ are significantly different $(P<0.05)$ by one-way ANOVA test.

oxidative stress, we tested if iron limitation could cause oxidative stress in C. crescentus.

Firstly, this was done by incubating exponential phase cells with dihydrorhodamine 123. This compound is able to penetrate the cells and becomes fluorescent as a result of intracellular oxidation. The cells were analyzed by fluorescence microscopy (Figures 4A,C,E,G,I,K) and light microscopy (Figures $4 \mathrm{~B}, \mathrm{D}, \mathrm{F}, \mathrm{H}, \mathrm{J}, \mathrm{L}$ ) to verify the amount of cells with visible fluorescence. While the wt cells in M2 showed no fluorescence (Figures 4A,B), when exposed to $100 \mu \mathrm{M}$ DP (Figures 4C,D) or grown in iron-limited medium (Figures 4E,F) all cells were fluorescent after $2 \mathrm{~h}$, confirming that iron limitation leads to an oxidative state. Interestingly, the fur mutant showed fluorescence both in M2 medium (Figures $\mathbf{4 G}, \mathbf{H}$ ) and in the presence of $100 \mu \mathrm{M}$ DP (Figures 4I,J), suggesting that Fur could be involved in preventing oxidative stress in C. crescentus. As a positive control, wt cells were incubated with $\mathrm{H}_{2} \mathrm{O}_{2}$ for 15 min (Figures 4K,L).

As a second confirmation of these results, determination of $\mathrm{H}_{2} \mathrm{O}_{2}$ in NA1000 cultures was carried out by measuring the rate of oxidation of Amplex Red in the presence of HRP. Cells from NA1000 cultures grown either in M2, or incubated for $3 \mathrm{~h}$ in iron limited M2 (no iron added), DP-treated M2 or DP-treated iron limited $\mathrm{M} 2$ were used for $\mathrm{H}_{2} \mathrm{O}_{2}$ determination (Table 1). The results showed that in the three cultures subject to iron limitation the rate of Amplex Red oxidation was 2- to 2.5-fold higher than in 

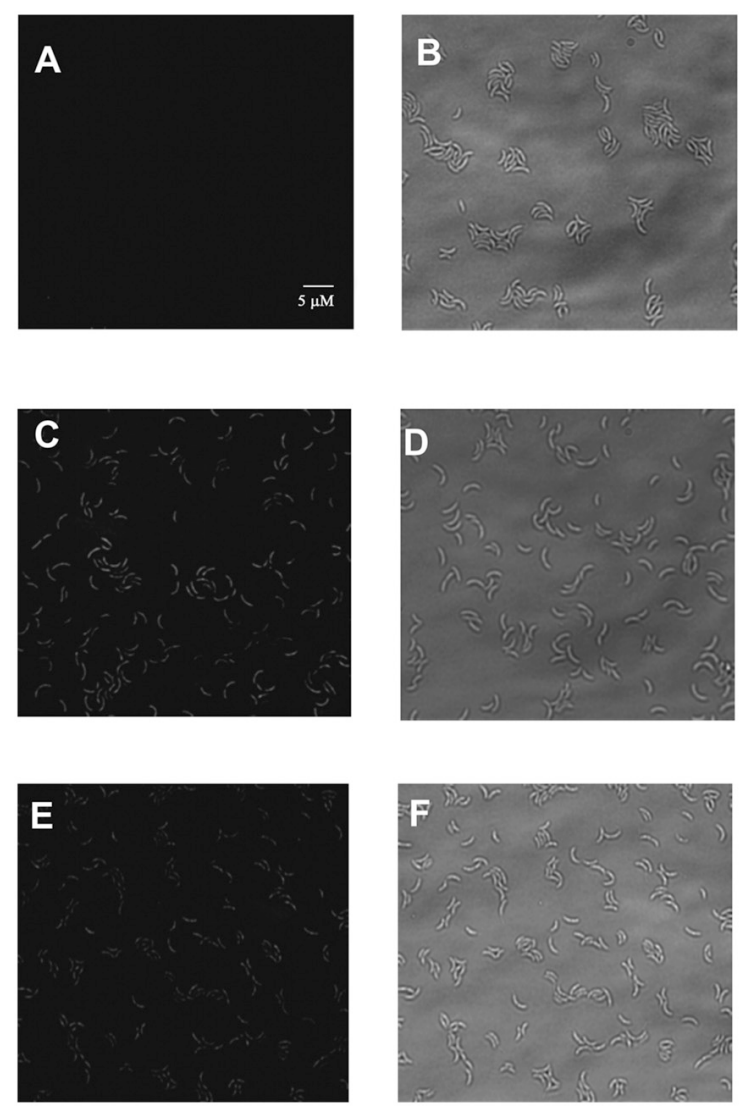
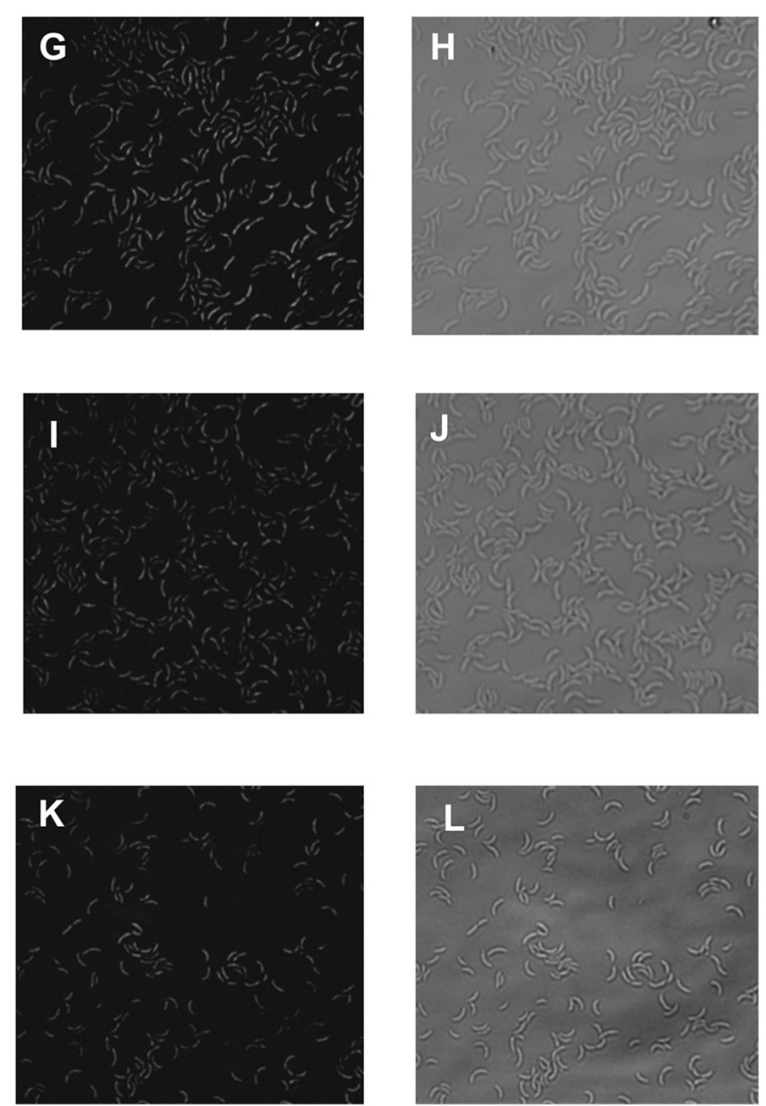

FIGURE 4 | Determination of the oxidative stress state of $C$. crescentus NA1000 in response to iron levels. Wild type NA1000 strain cultures were grown in M2 (A,B), DP-treated M2 (DP for 2 h) (C,D), or iron-limited M2 for 4 h (E,F); and cultures of the fur mutant were grown in M2 (G,H) or DP-treated M2 for 2 h (I,J). As a control, NA1000 cultures received $\mathrm{H}_{2} \mathrm{O}_{2}$ for $5 \mathrm{mM}$ and incubated for $15 \mathrm{~min} \mathbf{( K , L )}$. Samples were treated with dihydrorhodamine 123 and analyzed by fluorescence microscopy using a fluorescein filter (A,C,E,G,I,K) and under light microscopy (B,D,F,H,J,L).

M2 $(P<0.05)$, indicating that there is more endogenous $\mathrm{H}_{2} \mathrm{O}_{2}$, which could be measured in intact cells since it is freely diffusible.

Previously, it was shown that OxyR activates the expression the $C$. crescentus kat $G$ gene in response to hydrogen peroxide, and $k a t G$ was not regulated by Fur (Italiani et al., 2011). To determine whether the oxidative stress observed in the fur mutant and in the wt cells under iron limitation could lead to the OxyR-mediated response, the expression of kat $G$ was measured by RT-qPCR

TABLE 1 | Determination of hydrogen peroxide generated in C. crescentus NA1000 strain in different growth conditions.

\begin{tabular}{|c|c|}
\hline Growth condition & $\mathrm{pmol} \mathrm{H}_{2} \mathrm{O}_{2} / \mathrm{DO} / \mathrm{min}$ \\
\hline M2 & $20.81 \pm 2.43$ \\
\hline Iron limited M2ª,d & $51.50 \pm 3.17$ \\
\hline DP-treated $\mathrm{M} 2^{\mathrm{b}, \mathrm{d}}$ & $49.50 \pm 4.30$ \\
\hline DP-treated iron limited M2 $2^{a, b, d}$ & $42.91 \pm 1.67$ \\
\hline
\end{tabular}

${ }^{a}$ The cells pellets were resuspended in iron limited M2 (no iron added) in the same previous volume. See "Materials and Methods" section for details. ${ }^{b} T$ The culture was incubated with $100 \mu \mathrm{MDP}$ for $3 \mathrm{~h} .{ }^{\circ}$ The results are the average of two independent assays $\pm S D$. ${ }^{d}$ Significantly different from the M2 growth condition $(P<0.05)$ by one-way ANOVA test.
(Figure 5). However, there is still an increase in kat $G$ expression in the fur mutant in iron limited M2 as compared to M2, to a similar extent as in wt, suggesting that iron limitation is causing this induction.

Interestingly, several toxin-antitoxin encoding genes were highly upregulated in DP-treated cells, such as the ParD2/ParE2 (22.8- and 23.3-fold induction, respectively), the antitoxin protein RelB3 (23.6-fold), the HigB toxin (17.2-fold) and the DNA replication inhibitor toxin SocB/antitoxin SocA (17.2- and 14.0-fold induction, respectively). Previous work has shown that $\psi$-parDE2 and relBE3 are induced in response to oxidative stress (Fiebig et al., 2010). The higB gene is repressed by LexA, and HigB plays a role in mediating the intensity of the response to antibiotics together with the SOS response, in a regulatory interplay between LexA, HigBA, and AcrAB2-NodT (Kirkpatrick et al., 2016). In fact, in the DP-treated cells the acrAB2 genes were also induced threefold to fivefold.

\section{The SOS Response Is Induced Under Iron Deficiency}

The activation of SOS response in DP-treated C. crescentus cultures suggests that DNA damage is being generated in this 


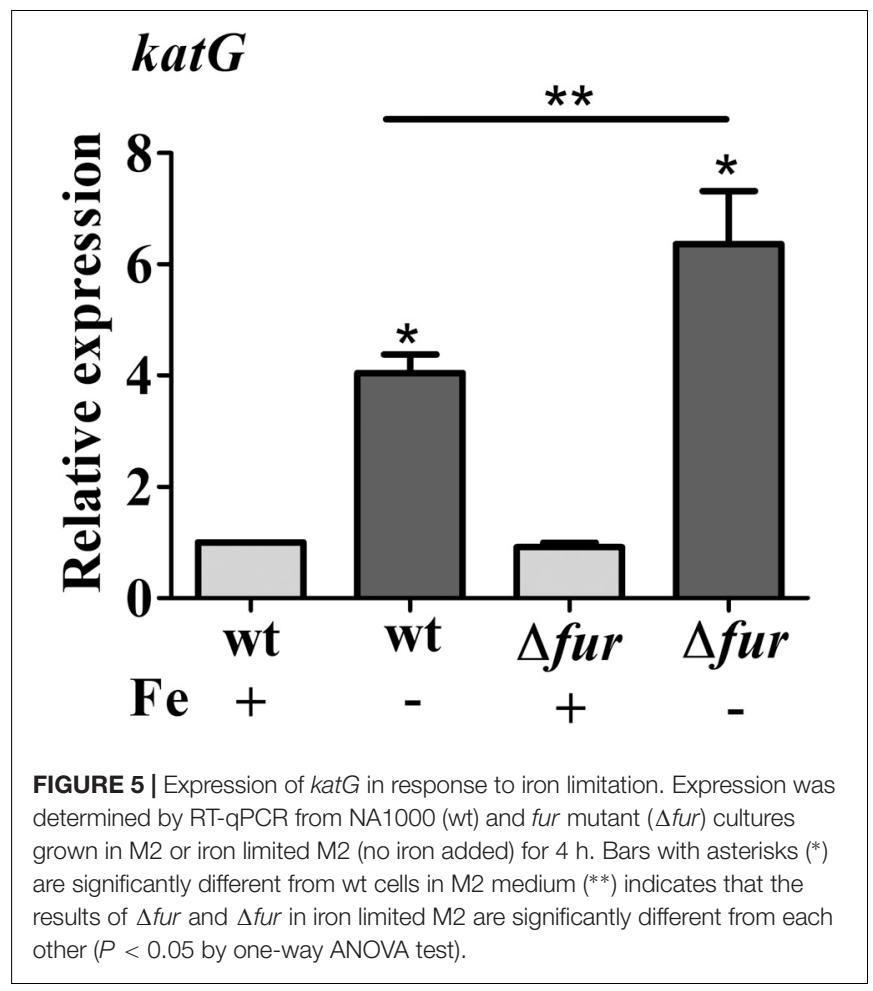

condition. To establish the role of Fur in the SOS signaling network, the transcripts levels of $\operatorname{lexA}$ and imuA were measured by RT-qPCR in wt and the fur mutant cells grown in either M2 medium or DP-treated M2 for $2 \mathrm{~h}$ (Figure 6A). In DP-treated NA1000 cultures, both transcripts were upregulated twofold (lexA) and fourfold (imuA) in wt cells, whereas in the fur mutant the expression was increased 3-and 16-fold comparing to wt in M2 medium, respectively. This induction is not observed in the recA mutant (Figure 6A). Since the fur mutant in M2 is under oxidative stress, but does not show an upregulation of the SOS response, this suggests that iron deficiency, and not the oxidative stress generated, is triggering the activation of SOS response. In fact, when both were grown in DP-treated medium, the SOS response is highly induced. The results also indicate that Fur may have a protective role against the resulting DNA damage, since the induction of both genes in the fur mutant was much higher than in the wt. To confirm that this effect was due to the iron limitation, the assays were repeated with the NA1000 strain grown in M2 or iron limited M2 (no iron added) (Figure 6B). The results were the same as with the DP-treated cultures, confirming that iron limitation is causing this response.

In order to directly measure the increase in the levels of DNA damage that could be occurring in response to iron deprivation, we measured the amount of 8-oxo-dG in the DNA of cells incubated in M2 or iron limited M2 (no iron added) for $12 \mathrm{~h}$. The results did not show any significant difference between the two treatments (M2, $8.45 \pm 5.48$-oxo-dG/10 5 dG, and M2 with no iron $8.18 \pm 2.718$-oxo-dG/10 $\mathrm{dG}$ ), although the levels of 8 oxo-dG detected were at the limit of detection. However, we have to consider that this type of base alteration may not be the most indicative for Caulobacter, and other types of oxidative lesions may be occurring.

In the mutagenesis tests, cultures of NA1000 and recA strains grown in M2 or iron limited M2 for $12 \mathrm{~h}$ were plated on PYE containing $100 \mu \mathrm{g} / \mathrm{ml}$ rifampicin. The results showed that the NA1000 cultures grown in iron limited medium presented an increase in the amount of Rif-resistant mutants (Figure 7), but this is not the case for the $\operatorname{rec} A$ mutant. These results indicate that iron deprivation leads to an increase in mutagenesis in C. crescentus, mediated by the SOS response. These results were consistent with the upregulation of the SOS genes in the same conditions, suggesting that increase in mutagenesis might be a result of error-prone DNA polymerases activity.

The activation of DNA repair enzymes protects the DNA against exogenous physical agents like UV light. In order to verify if cells under iron limitation were more resistant to UV light-induced damage due to the activation of the SOS response, midlog phase cultures of the NA1000 strain grown in M2 were divided into aliquots. One was left without addition, one received $100 \mu \mathrm{M}$ DP for $2 \mathrm{~h}$, and in two samples cells were centrifuged and resuspended in iron-limited M2 and further incubated for either $2 \mathrm{~h}$ or $4 \mathrm{~h}$ (Figure 8A). The cultures were then irradiated with $120 \mathrm{~J} / \mathrm{cm}^{2} \mathrm{UV}$ light, and the results showed that cells that were in iron limitation were more sensitive to UV than those without treatment. The same result was obtained with the fur mutant, (irradiated with $60 \mathrm{~J} / \mathrm{cm}^{2} \mathrm{UV}$ light), and the recA mutant (irradiated with $10 \mathrm{~J} / \mathrm{cm}^{2} \mathrm{UV}$ light) grown in $\mathrm{M} 2$ or iron limited M2 (Figures 8B,C). This indicates that the previous activation of the SOS response in iron limitation is not only not sufficient to mount a protection against damage caused by UV light, but the cells being already stressed contributes for a poor response to UV-generated stress.

\section{DISCUSSION}

The Fur regulon in C. crescentus grown in rich amino acid-based medium was extensively studied and its targets were determined in previous works (da Silva Neto et al., 2009, 2013). However, in minimal medium cells are in a metabolic biosynthetic mode, more similar to the oligotrophic environments where this bacterium thrives, so the consequences of iron limitation for C. crescentus grown in these conditions were investigated. The previous whole transcriptome study was carried out in PYE medium that received either $100 \mu \mathrm{M} \mathrm{FeSO}$ or of $100 \mu \mathrm{M} \mathrm{DP}$, which allowed the Fur regulon to be almost completely identified. In this work, the M2 medium was compared with DP-treated M2 medium, and allowed a complementary identification of iron limitation-induced genes. As expected, in defined M2 medium the genes for nitrogen and amino acid metabolism that were differentially expressed in DP-treated PYE were not identified, showing that the growth conditions affect the iron limitation response.

Among the iron limitation-induced genes were those encoding seven predicted small RNAs (sRNAs) (Landt et al., 2008; Schrader et al., 2014), being only one differentially expressed in the fur mutant compared to wt. The regulatory 


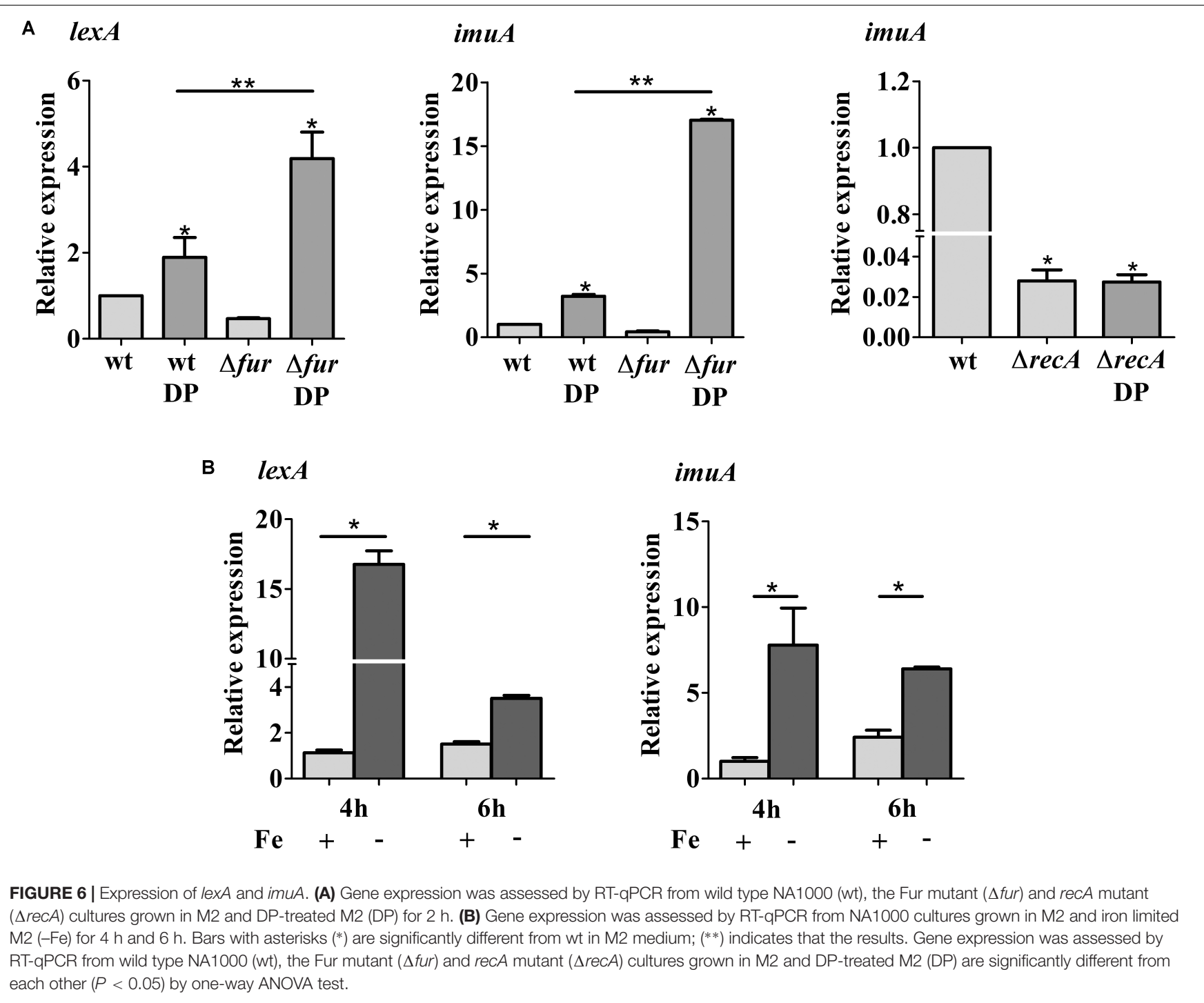

networks of several bacteria show that Fur is directly regulating the expression of iron-regulated regulatory RNAs (Masse and Gottesman, 2002; Wilderman et al., 2004; Masse et al., 2005, 2007; Mellin et al., 2007; Gaballa et al., 2008; Ghosh et al., 2017; Jackson et al., 2017). Although in this work we could detect only one Fur-regulated sRNA, we cannot exclude the possibility that there are some sRNAs that are regulated by Fur in other medium conditions. One caveat of the method used is that the RNA-seq was not strand-specific, therefore we may not detect all the differentially expressed sRNAs genes when they overlap with other genes. A more thorough investigation will bring light to this matter.

The genes encoding several transcription factors were upregulated in the DP-treated medium in a Fur-independent manner, which could be mediating the regulation of subsets of genes in response to the stress generated by iron limitation (Figure 9). Three extracytoplasmic function (ECF) sigma factors $\left(\sigma^{\mathrm{T}}, \sigma^{\mathrm{U}}\right.$, and $\left.\sigma^{\mathrm{E}}\right)$ regulate genes involved in protecting cells against stress, mainly oxidative damage. It has been shown that the $\sigma^{\mathrm{E}}$ is responsive to singlet oxygen, UV-A, cadmium, and organic hydroperoxide (Lourenço and Gomes, 2009). The SigT regulon is important for the response to osmotic and oxidative stresses (Alvarez-Martinez et al., 2007; Britos et al., 2011; Lourenço et al., 2011). Although sigT and most of its known regulon fell below our cutoff criterion in the fur mutant, sigT and $\operatorname{sig} U$ were highly activated in the DP-treated medium.

The induction of several genes related to oxidative stress response was in agreement with an endogenous oxidative stress state identified in $C$. crescentus cells under iron limitation. Since $k a t G$, the genes for superoxide dismutases, and several redoxins were upregulated in iron limitation, this indicates that the oxidative stress observed is caused by reactive oxygen species (ROS) of different types. The increase of oxidative stress under iron limitation has also been observed in the cyanobacterium Anabaena sp., but not in E. coli or B. subtilis. Iron starved Anabaena PCC7120 exhibit 100-fold increase of ROS compared 


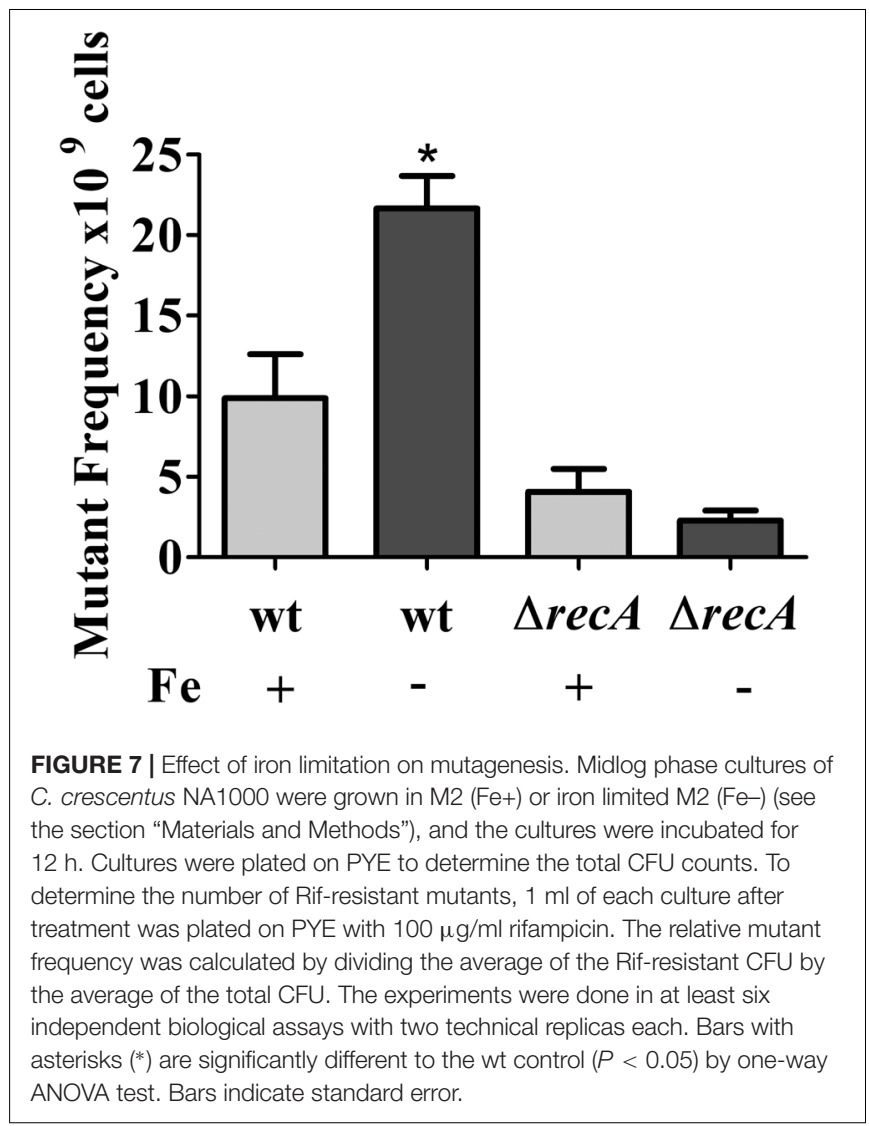

to non-starved cells (Latifi et al., 2005, 2009). Interestingly, a striking difference is that Caulobacter and Anabaena are strict aerobes, while E. coli and B. subtilis can grow in anaerobiosis. In Anabaena PCC7120, the FurA regulator has been shown to control genes related to protection against oxidative stress (Gonzalez et al., 2016). Contrasting with this, E. coli does not exhibit a significant increase in the ROS levels under iron limitation (Latifi et al., 2005), and it has been proposed that Fur represses iron uptake as an adaptive response to protect against hydroxyl radicals generated by Fenton chemistry (Faulkner and Helmann, 2011). In B. subtilis the upregulation of genes encoding enzymes for peroxide stress response ( $\operatorname{ahpCF}, \mathrm{mrgA}$, and $k a t A$ ) was observed in iron limitation (Baichoo et al., 2002); however, there was no increase of ROS levels in cells in these conditions (Latifi et al., 2005). The activation of these genes in B. subtilis can be explained by the fact that fur belongs to the PerR regulon (Baichoo et al., 2002; Faulkner and Helmann, 2011). Under iron deficiency PerR becomes an inactive repressor leading to the activation of fur, ahpCF, $m r g A$, and $k a t A$ gene expression (Faulkner and Helmann, 2011).

Interestingly, the gene encoding the ferritin-like DNA-binding protein Dps was induced specifically in DP-treated conditions. In E. coli Dps confers protection against oxidative stress caused by $\mathrm{H}_{2} \mathrm{O}_{2}$, and it was proposed that this is due its ability to bind DNA and inhibit the Fenton reaction. In C. crescentus, $d p s$ is regulated by SigT (Lourenço et al., 2011) and Dps has an important role in protecting the cell from oxidative stress (de Castro Ferreira et al., 2016). However, while in E. coli $d p$ s is induced by starvation and regulated by OxyR under oxidative stress (Almiron et al., 1992; Altuvia et al., 1994), in C. crescentus its regulation is not responsive to hydrogen peroxide, and is independent of Fur and OxyR (de Castro Ferreira et al., 2016). Its regulatory pattern indicates that its main role in C. crescentus is protecting the DNA against the damage generated in low iron condition.

The most remarkable difference in the stimulon determined in this work was the induction of the SOS regulon. The presence of single stranded DNA activates the recombinase RecA that stimulates the autocatalytic cleavage of the transcriptional repressor LexA, inducing the SOS regulon that is comprised of DNA repair genes. The SOS regulon in C. crescentus was previously characterized (da Rocha et al., 2008; Modell et al., 2011). Twenty-two genes involved in DNA repair (18 belonging to SOS regulon) were upregulated in DP-treated medium, including lexA and $\operatorname{rec} A$. We showed that the iron limitation induction of $i m u A$, as an SOS indicator gene, was dependent on RecA, so the induction of the SOS regulon was caused by the presence of DNA damage. Moreover, two genes (CCNA_01596 and CCNA_02930) that are induced by genotoxic treatments even though they do not belong to the SOS regulon are also upregulated in response to DP treatment (da Rocha et al., 2008; Modell et al., 2011, 2014), suggesting the response to DNA damage is broader than just the SOS system. Unexpectedly, despite the increase in expression of some genes belonging to the SOS regulon, cells grown in iron deficiency were more sensitive to UV. This could be explained by a distinct spectrum of specificity toward DNA lesions among the DNA repair systems, and different thresholds of induction. The response to UV damage is carried out mainly by the UvrABC system, which is part of the SOS response, but these genes (CCNA_02673, CCNA_02975, and CCNA_03076) were not induced in the DPtreated condition. In fact, these genes are poorly induced even in the absence of the lexA repressor ( $u v r A, 3.5$-fold; $u v r C, 1.7$ fold, and $u v r B$ not induced) (da Rocha et al., 2008). The DNA lesions caused by oxidative stress are distinct from the typical UVgenerated DNA lesions, requiring a specific set of repair enzymes, and the concomitant exposure to oxidative stress (generated by iron limitation) and UV is probably excessive for the cell responses.

The fact that iron is a cofactor for several enzymes necessary to help protecting against ROS (e.g., Fe-containing superoxide dismutases and heme-containing catalases/peroxidases) increases the complexity of this matter in what is the cause and what is the effect. The lack of iron could be disrupting the detoxification enzymes activity to a point when the cells start accumulating ROS. On the other hand, this does not seem to be the case in the fur mutant, since in this case iron uptake is constitutively active and these enzymes would be functional. A possible explanation for the increase in oxidative stress in low iron medium and in the fur mutant is an impairment of the respiratory function, mainly due to lower synthesis of the ironsulfur groups for enzymes of the respiratory chain. In eukaryotic cells dysfunctions that prevent the assembly of mitochondrial iron-sulfur components generate mtDNA instability and ROS, and have been treated with antioxidants (Figueira et al., 2013). 


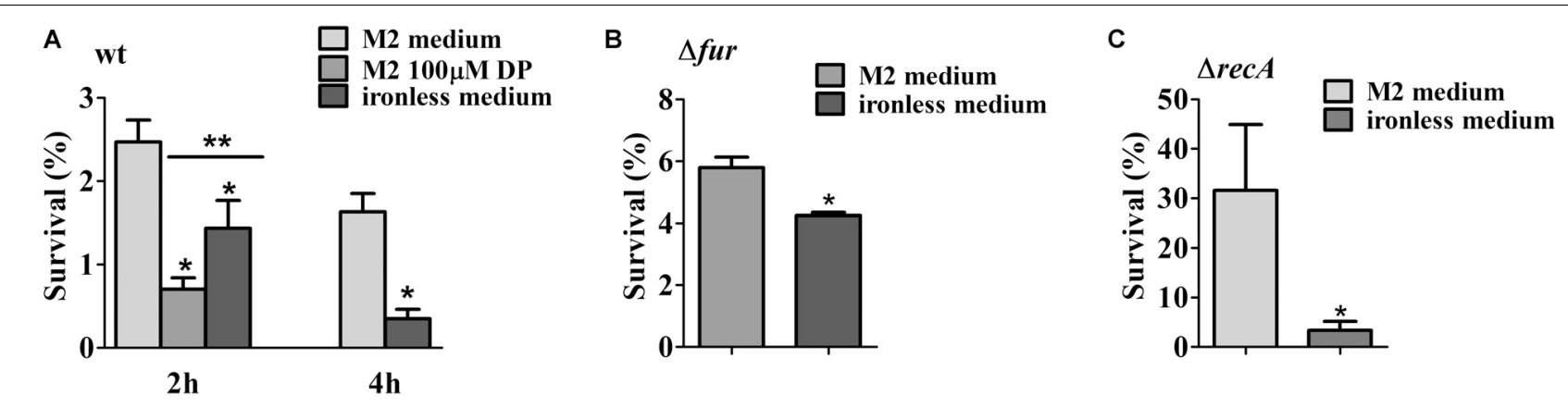

FIGURE 8 | Survival test of the NA1000 strain exposed to UV light. (A) NA1000 cultures were grown either in M2, DP-treated M2 for 2 h or iron-limited M2 for 2 h or $4 \mathrm{~h}$ and then irradiated with $120 \mathrm{~J} / \mathrm{cm}^{2}$ UV-light. (B) SP0057 cultures were grown either in M2, or iron-limited M2 for $4 \mathrm{~h}$ and then irradiated with $60 \mathrm{~J} / \mathrm{cm}^{2} \mathrm{UV}$-light. (C) GM10 cultures were grown either in M2, or iron-limited M2 for $4 \mathrm{~h}$ and then irradiated with $10 \mathrm{~J} / \mathrm{cm}^{2} \mathrm{UV}$-light. Survival was determined relative to the colony counts at time $0 \mathrm{~h}$, before irradiation (100\%). The results shown are the average of three independent experiments. Bars with asterisks $\left(^{*}\right)$ are significantly different to M2 medium; $(* *)$ indicates that DP-treated M2 and iron-limited M2 are significantly different $(P<0.05)$ by one-way ANOVA test (A) or Student's $t$-test (B,C).

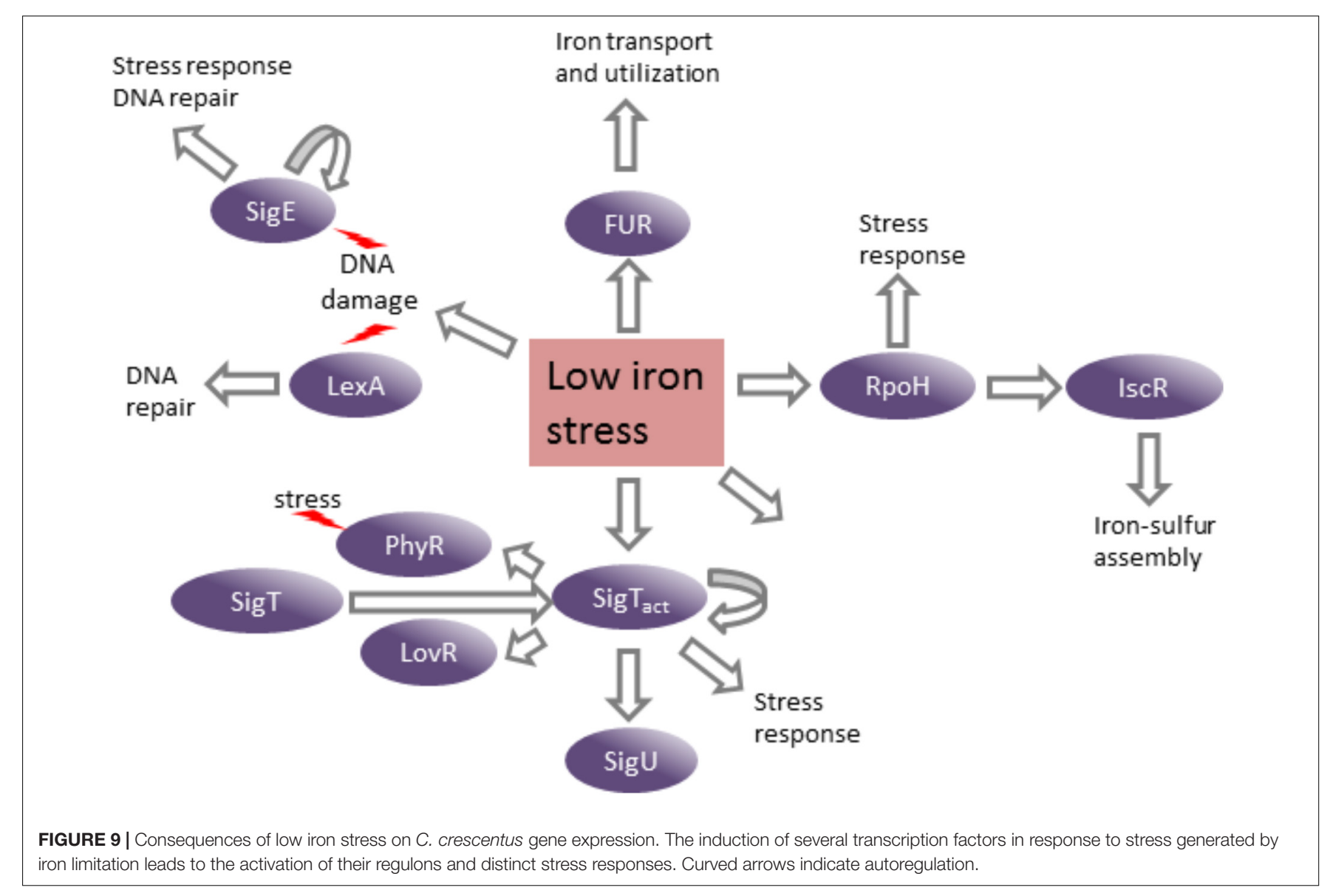

It was shown that in $C$. crescentus Fur directly activates the expression of $s d h C B A D$ (succinate dehydrogenase) and nuoA-N (NADH dehydrogenase) operons (da Silva Neto et al., 2009), and in this work several genes encoding cytochromes were downregulated in DP-treated medium and in the fur mutant, noteworthy the $c c o N O Q P$ and $c y d A B$ operons, which belong to the FixK regulon. Moreover, in DP-treated medium the operon encoding ATP synthase was also downregulated.
It has been reported in E. coli that the fur mutant showed a significant increase of mutagenesis in aerobic conditions and the addition of ferrozine did not reduce the frequency of mutagenesis, suggesting that this strain is suffering DNA damage (Touati et al., 1995). Furthermore, in the E. coli fur mutant the SOS response was not activated, and the mutagenesis was proposed to be due to recombination defects (Touati, 2000). It was suggested that the fur mutant has a permanent influx of 
iron, and this intracellular overload of iron could produce DNA damage that the addition of ferrozine was not able to avoid (Touati, 2000). We previously demonstrated that the C. crescentus fur null mutant is highly sensitive to exogenously added $\mathrm{H}_{2} \mathrm{O}_{2}$ and tert-butyl hydroperoxide (da Silva Neto et al., 2009). On the contrary to what was seen for E. coli, we observed that under iron limitation wild type $C$. crescentus generates oxidative stress, and the fur mutant is already in an endogenous oxidative state. Moreover, iron limitation (Figure 5 and Supplementary Figure S2) triggered the induction of SOS system in both strains, suggesting that DNA damage did not occur by excessive iron uptake. Agreeing with this, the SOS response was not induced even when it was exposed to $100 \mu \mathrm{M}$ of $\mathrm{FeSO}_{4}$ (Supplementary Figure S2). Taken together, these results suggest that in C. crescentus DNA damage is not generated by excess of free iron, although we cannot exclude the possibility that high endogenous iron levels are generating the oxidative stress observed in the fur mutant.

The increase in DNA damage observed in C. crescentus could be a consequence of the oxidative stress generated under iron limitation. Previous studies had shown that the lesions caused by $\mathrm{H}_{2} \mathrm{O}_{2}$ in $E$. coli are dependent on iron concentration, with higher $\mathrm{H}_{2} \mathrm{O}_{2}$ concentrations being necessary for the maximal induction of SOS response in low iron condition (Asad and Leitao, 1991; Asad et al., 1997). Furthermore, E. coli lexA and recA mutants are sensitive to $\mathrm{H}_{2} \mathrm{O}_{2}$ under iron limitation, suggesting that the induction of SOS response is important when the cells are treated with $\mathrm{H}_{2} \mathrm{O}_{2}$ in low iron condition (Asad et al., 1997). We cannot exclude the possibility that the lower levels of intracellular iron could affect not only iron metabolism, but also other ions like copper or zinc, that could lead to DNA damage. It was previously reported that high $\mathrm{H}_{2} \mathrm{O}_{2}$ concentration under iron limitation leads to an increase of $\mathrm{Cu}$ ions inside the cells causing DNA damage and the activation of SOS response (Almeida et al., 2000). However, we have to take into account that an increase in the oxidative stress was not observed in E. coli under iron limitation. At any case, the induction of DNA repair genes observed did not protect the cells against UV-light exposure, suggesting that either the SOS response is not at its maximum, or there is a synergistic effect of both treatments in generating DNA damage.

The C. crescentus fur mutant in M2 is under oxidative stress, but this does not lead to the induction of SOS response, since the lexA and imuA transcript levels are repressed 0.5-fold in the fur mutant as compared to wild type in iron sufficiency. Moreover, in the DP-treated medium the lexA and imuA transcript levels are twofold and eightfold higher in the fur mutant, respectively, than wt cells in the same condition. These results suggest that Fur is involved in their regulation, probably indirectly. In Anabaena sp 7120 FurA acts as repressor of a single-strand DNA binding protein (SSB) that plays a role in recombination and repair by protecting the single-stranded DNA, indicating a possible role of Fur in DNA repair in cyanobacteria (Kirti et al., 2017).

The results of this work showed here for the first time that iron deprivation is causing oxidative stress and DNA damage in C. crescentus, triggering the activation of several stress response pathways. Further experimentation will be necessary to establish whether these phenotypes are or not related, and whether this may be a common trend to other bacteria.

\section{DATA AVAILABILITY STATEMENT}

The genomic datasets analyzed for this study can be found in NCBI Assembly (ASM2200v1; GCF_000022005.1). The RNAseq datasets generated for this study can be found in the NCBI Sequence Read Archive under accession code SRP136695.

\section{AUTHOR CONTRIBUTIONS}

LL performed the experiments and analyzed the data. LS conducted the RNA-seq experiments. RR, AL, and TK performed the bioinformatics analyses. NMS performed the qRT-PCR experiments. TA performed the $\mathrm{H}_{2} \mathrm{O}_{2}$ quantification assays. MS and MHGM performed the 8-oxo-dG quantification assays. MVM designed the experiments and analyzed the data. LL and MVM wrote the manuscript. All authors read, revised, and approved the final manuscript.

\section{FUNDING}

This work was supported by São Paulo Research Foundation (FAPESP, grant 2014/04046-8) and Conselho Nacional de Desenvolvimento Científico e Tecnológico (CNPq-Brazil, grant 306558/2013-0). During the course of this work, RR and NMS were supported by FAPESP masters fellowship grants 2016/06378-3 and 2017/02127-9, respectively, LL by a FAPESP postdoctoral fellowship grant $2015 / 07386-7$, LS by a postdoctoral fellowship grant 2015/1461678 from Coordenação de Aperfeiçoamento de Pessoal de Nível Superior (CAPES), AL by a FAPESP doctorate fellowship grant 2017/03052-2, TK by FAPESP research grant 2015/21038-1, and MVM was partially supported by CNPq-Brazil.

\section{ACKNOWLEDGMENTS}

We are grateful to Frederico Gueiros Filho and Ana Carolina Cauz for assistance with the microscopy experiments, Luis Eduardo Soares Netto and Fernando Gomes for assistance with the $\mathrm{H}_{2} \mathrm{O}_{2}$ determination, José Freire da Silva Neto and Rodrigo Galhardo for revising the manuscript and for helpful comments during the course of this work, and R. Galhardo and members of the Galhardo lab for assistance with the UV and mutagenesis assays.

\section{SUPPLEMENTARY MATERIAL}

The Supplementary Material for this article can be found online at: https://www.frontiersin.org/articles/10.3389/fmicb.2018. 02014/full\#supplementary-material 


\section{REFERENCES}

Almeida, C. E., Galhardo, R. S., Felicio, D. L., Cabral-Neto, J. B., and Leitao, A. C. (2000). Copper ions mediate the lethality induced by hydrogen peroxide in low iron conditions in Escherichia coli. Mutat. Res. 460, 61-67. doi: 10.1016/S09218777(00)00014-8

Almiron, M., Link, A. J., Furlong, D., and Kolter, R. (1992). A novel DNA-binding protein with regulatory and protective roles in starved Escherichia coli. Genes Dev. 6, 2646-2654. doi: 10.1101/gad.6.12b.2646

Altuvia, S., Almiron, M., Huisman, G., Kolter, R., and Storz, G. (1994). The dps promoter is activated by OxyR during growth and by IHF and sigma(s) in stationary phase. Mol. Microbiol. 13, 265-272. doi: 10.1111/j.1365-2958.1994. tb00421.x

Alvarez-Martinez, C. E., Lourenco, R. F., Baldini, R. L., Laub, M. T., and Gomes, S. L. (2007). The ECF sigma factor sigma(T) is involved in osmotic and oxidative stress responses in Caulobacter crescentus. Mol. Microbiol. 66, 1240-1255. doi: 10.1111/j.1365-2958.2007.06005.x

Andrews, S. C., Robinson, A. K., and Rodriguez-Quinones, F. (2003). Bacterial iron homeostasis. FEMS Microbiol. Rev. 27, 215-237. doi: 10.1016/S0168-6445(03) 00055-X

Asad, L. M., Asad, N. R., Silva, A. B., de Almeida, C. E., and Leitao, A. C. (1997) Role of SOS and OxyR systems in the repair of Escherichia coli submitted to hydrogen peroxide under low iron conditions. Biochimie 79, 359-364 doi: 10.1016/S0300-9084(97)80030-2

Asad, N. R., and Leitao, A. C. (1991). Effects of metal ion chelators on DNA strand breaks and inactivation produced by hydrogen peroxide in Escherichia coli: detection of iron-independent lesions. J. Bacteriol. 173, 2562-2568. doi: 10.1128/jb.173.8.2562-2568.1991

Baichoo, N., Wang, T., Ye, R., and Helmann, J. D. (2002). Global analysis of the Bacillus subtilis Fur regulon and the iron starvation stimulon. Mol. Microbiol. 45, 1613-1629. doi: 10.1046/j.1365-2958.2002.03113.x

Balhesteros, H., Shipelskiy, Y., Long, N. J., Majumdar, A., Katz, B. B., Santos, N. M., et al. (2017). TonB-dependent heme/hemoglobin utilization by Caulobacter crescentus HutA. J. Bacteriol. 199:e00723-16. doi: 10.1128/JB.00723-16

Barros, M. H., Netto, L. E., and Kowaltowski, A. J. (2003). H(2)O(2) generation in Saccharomyces cerevisiae respiratory pet mutants: effect of cytochrome c. Free Radic. Biol. Med. 35, 179-188. doi: 10.1016/S0891-5849(03)00307-1

Beauchene, N. A., Mettert, E. L., Moore, L. J., Keles, S., Willey, E. R., and Kiley, P. J. (2017). O2 availability impacts iron homeostasis in Escherichia coli. Proc. Natl. Acad. Sci. U.S.A. 114, 12261-12266. doi: 10.1073/pnas.1707189114

Beauchene, N. A., Myers, K. S., Chung, D., Park, D. M., Weisnicht, A. M., Keles, S. et al. (2015). Impact of Anaerobiosis on expression of the iron-responsive fur and RyhB regulons. mBio 6:e01947-15. doi: 10.1128/mBio.01947-15

Beinert, H., Holm, R. H., and Munck, E. (1997). Iron-sulfur clusters: nature's modular, multipurpose structures. Science 277, 653-659. doi: 10.1126/science. 277.5326 .653

Bolger, A. M., Lohse, M., and Usadel, B. (2014). Trimmomatic: a flexible trimmer for Illumina sequence data. Bioinformatics 30, 2114-2120. doi: 10 . 1093/bioinformatics/btu170

Britos, L., Abeliuk, E., Taverner, T., Lipton, M., McAdams, H., and Shapiro, L. (2011). Regulatory response to carbon starvation in Caulobacter crescentus. PLoS One 6:e18179. doi: 10.1371/journal.pone.0018179

Chandrangsu, P., Rensing, C., and Helmann, J. D. (2017). Metal homeostasis and resistance in bacteria. Nat. Rev. Microbiol. 15, 338-350. doi: 10.1038/nrmicro. 2017.15

da Rocha, R. P., Paquola, A. C., Marques, Mdo. V., Menck, C. F., and Galhardo, R. S. (2008). Characterization of the SOS regulon of Caulobacter crescentus J. Bacteriol. 190, 1209-1218. doi: 10.1128/JB.01419-07

da Silva Neto, J. F., Braz, V. S., Italiani, V. C., and Marques, M. V. (2009). Fur controls iron homeostasis and oxidative stress defense in the oligotrophic alphaproteobacterium Caulobacter crescentus. Nucleic Acids Res. 37, 4812-4825. doi: 10.1093/nar/gkp509

da Silva Neto, J. F., Lourenco, R. F., and Marques, M. V. (2013). Global transcriptional response of Caulobacter crescentus to iron availability. BMC Genomics 14:549. doi: 10.1186/1471-2164-14-549

de Castro Ferreira, I. G., Rodrigues, M. M., da Silva Neto, J. F., Mazzon, R. R., and do Valle Marques, M. (2016). Role and regulation of ferritin-like proteins in iron homeostasis and oxidative stress survival of Caulobacter crescentus. Biometals 29, 851-862. doi: 10.1007/s10534-016-9956-y

Ely, B. (1991). Genetics of Caulobacter crescentus. Methods Enzymol. 204, 372-384. doi: 10.1016/0076-6879(91)04019-K

Evinger, M., and Agabian, N. (1977). Envelope-associated nucleoid from Caulobacter crescentus stalked and swarmer cells. J. Bacteriol. 132, 294-301.

Faulkner, M. J., and Helmann, J. D. (2011). Peroxide stress elicits adaptive changes in bacterial metal ion homeostasis. Antioxid. Redox Signal. 15, 175-189. doi: 10.1089/ars.2010.3682

Fiebig, A., Castro Rojas, C. M., Siegal-Gaskins, D., and Crosson, S. (2010). Interaction specificity, toxicity and regulation of a paralogous set of ParE/RelEfamily toxin-antitoxin systems. Mol. Microbiol. 77, 236-251. doi: 10.1111/j. 1365-2958.2010.07207.x

Figueira, T. R., Barros, M. H., Camargo, A. A., Castilho, R. F., Ferreira, J. C., Kowaltowski, A. J., et al. (2013). Mitochondria as a source of reactive oxygen and nitrogen species: from molecular mechanisms to human health. Antioxid. Redox Signal. 18, 2029-2074. doi: 10.1089/ars.2012.4729

Fillat, M. F. (2014). The FUR (ferric uptake regulator) superfamily: diversity and versatility of key transcriptional regulators. Arch. Biochem. Biophys. 546, 41-52. doi: 10.1016/j.abb.2014.01.029

Foreman, R., Fiebig, A., and Crosson, S. (2012). The LovK-LovR two-component system is a regulator of the general stress pathway in Caulobacter crescentus. J. Bacteriol. 194, 3038-3049. doi: 10.1128/JB.00182-12

Gaballa, A., Antelmann, H., Aguilar, C., Khakh, S. K., Song, K. B., Smaldone, G. T., et al. (2008). The Bacillus subtilis iron-sparing response is mediated by a Furregulated small RNA and three small, basic proteins. Proc. Natl. Acad. Sci. U.S.A. 105, 11927-11932. doi: 10.1073/pnas.0711752105

Galhardo, R. S., Rocha, R. P., Marques, M. V., and Menck, C. F. (2005). An SOSregulated operon involved in damage-inducible mutagenesis in Caulobacter crescentus. Nucleic Acids Res. 33, 2603-2614. doi: 10.1093/nar/gki551

Garcia, C. C., Freitas, F. P., Di Mascio, P., and Medeiros, M. H. (2010). Ultrasensitive simultaneous quantification of 1,N2-etheno- 2 -deoxyguanosine and 1,N2-propano-2'-deoxyguanosine in DNA by an online liquid chromatography-electrospray tandem mass spectrometry assay. Chem. Res. Toxicol. 23, 1245-1255. doi: 10.1021/tx1001018

Ghosh, S., Dureja, C., Khatri, I., Subramanian, S., Raychaudhuri, S., and Ghosh, S. (2017). Identification of novel small RNAs in Burkholderia cenocepacia KC-01 expressed under iron limitation and oxidative stress conditions. Microbiology doi: 10.1099/mic.0.000566. [Epub ahead of print].

Gonzalez, A., Bes, M. T., Peleato, M. L., and Fillat, M. F. (2016). Expanding the role of FurA as essential global regulator in Cyanobacteria. PLoS One 11:e0151384 doi: 10.1371/journal.pone.0151384

Huber, W., Carey, V. J., Gentleman, R., Anders, S., Carlson, M., Carvalho, B. S., et al. (2015). Orchestrating high-throughput genomic analysis with Bioconductor. Nat. Methods 12, 115-121. doi: 10.1038/nmeth.3252

Italiani, V. C., da Silva Neto, J. F., Braz, V. S., and Marques, M. V. (2011). Regulation of catalase-peroxidase KatG is OxyR dependent and Fur independent in Caulobacter crescentus. J. Bacteriol. 193, 1734-1744. doi: 10 1128/JB.01339-10

Jackson, L. A., Day, M., Allen, J., Scott, E. II, and Dyer, D. W. (2017). Ironregulated small RNA expression as Neisseria gonorrhoeae FA 1090 transitions into stationary phase growth. BMC Genomics 18:317. doi: 10.1186/s12864-0173684-8

Kanehisa, M., Furumichi, M., Tanabe, M., Sato, Y., and Morishima, K. (2017). KEGG: new perspectives on genomes, pathways, diseases and drugs. Nucleic Acids Res 45, D353-D361. doi: 10.1093/nar/gkw1092

Kirkpatrick, C. L., Martins, D., Redder, P., Frandi, A., Mignolet, J., Chapalay, J. B., et al. (2016). Growth control switch by a DNA-damage-inducible toxinantitoxin system in Caulobacter crescentus. Nat. Microbiol. 1:16008. doi: 10. 1038/nmicrobiol.2016.8

Kirti, A., Kumar, A., and Rajaram, H. (2017). Differential regulation of $s s b$ genes in the nitrogen-fixing cyanobacterium, Anabaena sp. strain PCC71201. J. Phycol. 53, 322-332. doi: 10.1111/jpy.12500

Landt, S. G., Abeliuk, E., McGrath, P. T., Lesley, J. A., McAdams, H. H., and Shapiro, L. (2008). Small non-coding RNAs in Caulobacter crescentus. Mol. Microbiol. 68, 600-614. doi: 10.1111/j.1365-2958.2008. 06172.x 
Langmead, B., Trapnell, C., Pop, M., and Salzberg, S. L. (2009). Ultrafast and memory-efficient alignment of short DNA sequences to the human genome. Genome Biol. 10:R25. doi: 10.1186/gb-2009-10-3-r25

Latifi, A., Jeanjean, R., Lemeille, S., Havaux, M., and Zhang, C. C. (2005). Iron starvation leads to oxidative stress in Anabaena sp. strain PCC 7120. J. Bacteriol. 187, 6596-6598. doi: 10.1128/JB.187.18.6596-6598.2005

Latifi, A., Ruiz, M., and Zhang, C. C. (2009). Oxidative stress in cyanobacteria. FEMS Microbiol. Rev. 33, 258-278. doi: 10.1111/j.1574-6976.2008.00134.x

Lawrence, M., Huber, W., Pages, H., Aboyoun, P., Carlson, M., Gentleman, R., et al. (2013). Software for computing and annotating genomic ranges. PLoS Comput. Biol. 9:e1003118. doi: 10.1371/journal.pcbi.1003118

Lee, J. W., and Helmann, J. D. (2007). Functional specialization within the Fur family of metalloregulators. Biometals 20, 485-499. doi: 10.1007/s10534-0069070-7

Li, H., Handsaker, B., Wysoker, A., Fennell, T., Ruan, J., Homer, N., et al. (2009). The sequence alignment/map format and SAMtools. Bioinformatics 25, 20782079. doi: 10.1093/bioinformatics/btp352

Lourenço, R. F., and Gomes, S. L. (2009). The transcriptional response to cadmium, organic hydroperoxide, singlet oxygen and UV-A mediated by the sigmaE-ChrR system in Caulobacter crescentus. Mol. Microbiol. 72, 1159-1170. doi: 10.1111/j.1365-2958.2009.06714.x

Lourenço, R. F., Kohler, C., and Gomes, S. L. (2011). A two-component system, an anti-sigma factor and two paralogous ECF sigma factors are involved in the control of general stress response in Caulobacter crescentus. Mol. Microbiol. 80, 1598-1612. doi: 10.1111/j.1365-2958.2011.07668.x

Love, M. I., Huber, W., and Anders, S. (2014). Moderated estimation of fold change and dispersion for RNA-seq data with DESeq2. Genome Biol. 15:550. doi: 10.1186/s13059-014-0550-8

Masse, E., and Gottesman, S. (2002). A small RNA regulates the expression of genes involved in iron metabolism in Escherichia coli. Proc. Natl. Acad. Sci. U.S.A. 99, 4620-4625. doi: 10.1073/pnas.032066599

Masse, E., Salvail, H., Desnoyers, G., and Arguin, M. (2007). Small RNAs controlling iron metabolism. Curr. Opin. Microbiol. 10, 140-145. doi: 10.1016/ j.mib.2007.03.013

Masse, E., Vanderpool, C. K., and Gottesman, S. (2005). Effect of RyhB small RNA on global iron use in Escherichia coli. J. Bacteriol. 187, 6962-6971. doi: 10.1128/JB.187.20.6962-6971.2005

Mellin, J. R., Goswami, S., Grogan, S., Tjaden, B., and Genco, C. A. (2007). A novel fur- and iron-regulated small RNA, NrrF, is required for indirect fur-mediated regulation of the $s d h A$ and $s d h C$ genes in Neisseria meningitidis. J. Bacteriol. 189, 3686-3694. doi: 10.1128/JB.01890-06

Miller, J. H. (1972). Experiments in Molecular Genetics. Cold Spring, NY: Cold Spring Harbor Laboratoy Press.
Modell, J. W., Hopkins, A. C., and Laub, M. T. (2011). A DNA damage checkpoint in Caulobacter crescentus inhibits cell division through a direct interaction with FtsW. Genes Dev. 25, 1328-1343. doi: 10.1101/gad.2038911

Modell, J. W., Kambara, T. K., Perchuk, B. S., and Laub, M. T. (2014). A DNA damage-induced, SOS-independent checkpoint regulates cell division in Caulobacter crescentus. PLoS Biol. 12:e1001977. doi: 10.1371/journal.pbio. 1001977

Pfaffl, M. W. (2001). A new mathematical model for relative quantification in real-time RT-PCR. Nucleic Acids Res. 29:e45. doi: 10.1093/nar/29. 9.e45

Sanchez, A. B., Garcia, C. C. M., Freitas, F. P., Batista, G. L., Lopes, F. S., Carvalho, V. H., et al. (2018). DNA adduct formation in the lungs and brain of rats exposed to low concentrations of [(13)C2]-acetaldehyde. Chem. Res. Toxicol. 31, 332-339. doi: 10.1021/acs.chemrestox.8b00016

Schrader, J. M., Zhou, B., Li, G. W., Lasker, K., Childers, W. S., Williams, B., et al. (2014). The coding and noncoding architecture of the Caulobacter crescentus genome. PLoS Genet. 10:e1004463. doi: 10.1371/journal.pgen.1004463

Touati, D. (2000). Iron and oxidative stress in bacteria. Arch. Biochem. Biophys. 373, 1-6. doi: 10.1006/abbi.1999.1518

Touati, D., Jacques, M., Tardat, B., Bouchard, L., and Despied, S. (1995). Lethal oxidative damage and mutagenesis are generated by iron in delta fur mutants of Escherichia coli: protective role of superoxide dismutase. J. Bacteriol. 177, 2305-2314. doi: 10.1128/jb.177.9.2305-2314.1995

Untergasser, A., Cutcutache, I., Koressaar, T., Ye, J., Faircloth, B. C., Remm, M., et al. (2012). Primer3-new capabilities and interfaces. Nucleic Acids Res. 40:e115. doi: 10.1093/nar/gks596

Wilderman, P. J., Sowa, N. A., FitzGerald, D. J., FitzGerald, P. C., Gottesman, S., Ochsner, U. A., et al. (2004). Identification of tandem duplicate regulatory small RNAs in Pseudomonas aeruginosa involved in iron homeostasis. Proc. Natl. Acad. Sci. U.S.A. 101, 9792-9797. doi: 10.1073/pnas.04034 23101

Conflict of Interest Statement: The authors declare that the research was conducted in the absence of any commercial or financial relationships that could be construed as a potential conflict of interest.

Copyright (C) 2018 Leaden, Silva, Ribeiro, dos Santos, Lorenzetti, Alegria, Schulz, Medeiros, Koide and Marques. This is an open-access article distributed under the terms of the Creative Commons Attribution License (CC BY). The use, distribution or reproduction in other forums is permitted, provided the original author(s) and the copyright owner(s) are credited and that the original publication in this journal is cited, in accordance with accepted academic practice. No use, distribution or reproduction is permitted which does not comply with these terms. 